MIGRACIONES INTERNACIONALES, VOL. 12, ART. 14, 2021 e-ISSN 2594-0279 https://doi.org/10.33679/rmi.v1i1.2300

\title{
Migración venezolana reciente en Argentina: una política migratoria selectiva en el contexto del giro migratorio restrictivo
}

\section{Recent Venezuelan Migration to Argentina: A Selective Immigration Policy in the Context of the Immigration Restrictive Turn}

\section{María Dolores Linares ${ }^{1}$}

\section{RESUMEN}

El objetivo de este artículo es describir los instrumentos y las acciones que constituyen la política pública selectiva para migrantes venezolanos en la Argentina en el período 2017-2019, aplicada en el marco del giro restrictivo de la política migratoria general de la administración del presidente Macri (2015-2019). Mediante un relevo de instrumentos normativos y de acciones de política pública, complementado con un abordaje cualitativo, se busca comprobar la existencia de una política migratoria selectiva, descubrir los criterios de selección aplicados, e indicar las tensiones entre la política migratoria general y la selectiva.

Palabras clave: 1. política migratoria, 2. política migratoria selectiva, 3. administración pública, 4. migración venezolana, 5. Argentina.

\section{ABSTACT}

The purpose of this article is to describe instruments and actions that constitute the selective public policy towards Venezuelan migrants in Argentina between 2017-2019, in the context of the restrictive turn of the immigration policy under President Macri's administration (20152019). Through the change of normative instruments and public policy actions, complemented by a qualitative approach, we aim to verify the existence of a selective immigration policy, discover the selection criteria applied, and indicate the tensions between general and selective immigration policy.

Keywords: 1. immigration policy, 2. selective immigration policy, 3. public administration, 4. Venezuelan migration, 5. Argentina.

Fecha de recepción: 20 de febrero de 2020

Fecha de aceptación: 10 de julio de 2020

Fecha de publicación web: 30 de julio de 2021

1 Instituto de Estudios Históricos y Sociales de La Pampa, Argentina, linares.dolores@gmail.com, https://orcid.org/0000-0003-1814-9949 
2 Migración venezolana reciente en Argentina: una política migratoria selectiva... Linares, M. D.

\section{INTRODUCCIÓN}

La migración proveniente de la República Bolivariana de Venezuela hacia la República Argentina en los últimos cinco años presenta características que la distinguen de otros colectivos nacionales, especialmente - pero no exclusivamente- por su masividad y por la alta cualificación de los sujetos migrantes. Los pedidos de residencia de venezolanos en Argentina se quintuplicaron entre 2015 y 2017 y, según las estadísticas de la Dirección Nacional de Migraciones (en adelante DNM), las radicaciones de venezolanos resueltas en el año 2018 sumaban 70531 (Dirección Nacional de Migraciones [DNM], s/fa, s/fb y s/fc), superando numéricamente a los pedidos de radicación de ciudadanos de países vecinos.

Históricamente, la población venezolana residente en la Argentina era muy escasa y por esa razón no figuró detallada en los censos nacionales del 2011 y 2010. Según las estadísticas de la DNM se estima que, de más de 12000 venezolanos residiendo en Argentina en 2015, se llegó a 130000 en el año 2018 (DNM, s/f, s/fa, s/fb y s/fc) y a 251200 a principios del año 2021según el sitio web del Alto Comisionado de las Naciones Unidas para los Refugiados (ACNUR) (UNHCR, 2021). Este flujo correspondería al arribo de la tercera y la cuarta olas migratorias de venezolanos iniciadas en 2013 y 2016 respectivamente (Koechlin, Vega y Solórzano, 2018) $)^{2}$. Las primeras investigaciones sobre la reciente migración venezolana en Argentina dan cuenta de la alta incidencia de profesionales venezolanos, una inserción laboral en sectores informales o precarizados (Pedone y Mallimaci, 2019) y su concentración en las grandes ciudades (Biderbast y Nuñez, 2018). Estos trabajos establecen que uno de los factores de atracción es la posibilidad de radicación y de permanecer en Argentina de manera regular. Esto es factible gracias a la Ley de Migraciones 25.871 (Ley de Migraciones $N^{\circ} 25.871$ ), que garantiza la migración como un derecho humano que el Estado debe resguardar y que reconoce a los migrantes el derecho de acceso a la salud, a la educación y a la justicia, sin importar su condición documentaria.

Sin embargo, desde la administración del presidente Mauricio Macri (2015-2019), la política migratoria argentina ha asumido características más restrictivas, especialmente a partir del Decreto de Necesidad y Urgencia No 70 del año 2017 (DNU No 70, 2017). Según numerosos autores (Canelo, Gavazzo y Nejamkis, 2018; García y Nejamkis, 2018; Penchaszadeh y García, 2018) este decreto, que se fundamenta en la vinculación entre la migración y delitos graves como el narcotráfico, significa una regresión en términos de respeto a los derechos humanos al permitir la deportación express, con serias consecuencias a la unión de familias migrantes o mixtas (Muñoz, 2017).

Pese al viraje restrictivo de la política migratoria que implica un recorte de derechos (García y Nejamkis, 2018) y el posible regreso a la concepción de Estado gendarme (Ceriani Cernadas,

\footnotetext{
${ }^{2}$ Según los autores, la primera ola, compuesta por profesionales e investigadores de clase alta, emigra luego de la asunción del presidente Hugo Chávez Frías, hacia EE. UU., España y Francia. Las medidas socio económicas del presidente a partir de 2007 originaron la segunda ola y la asunción del presidente Nicolás Maduro en el año 2013 inició la tercera ola, cuando profesionales de clase media migraron a países de Sudamérica en busca de mejores oportunidades. La cuarta ola, desde el 2016, se compone de personas de clase media y baja que se dirigen a países cercanos.
} 
$2016)^{3}$, la migración venezolana no sólo no ha sido afectada sino que, por el contrario, ha sido de las pocas beneficiadas a partir de una serie de instrumentos de políticas públicas elaboradas entre los años 2018 y 2019. Basándonos en el concepto de Instrumentos de Políticas Públicas (Isuani, 2012) en tanto herramienta analítica, el objetivo de este artículo es indicar y describir estos instrumentos destinados al colectivo de venezolanos así como las acciones concretas promovidas desde la administración del presidente Macri, a la luz del cambio restrictivo de la política migratoria general. Se busca comprobar la existencia de una política migratoria selectiva dirigida a este colectivo y caracterizarla, descubriendo los criterios de selección aplicados y las tensiones entre la política migratoria general y la selectiva.

Se toman como antecedentes las investigaciones que buscan problematizar las relaciones entre el Estado (en sus diferentes escalas de análisis) y los migrantes internacionales. Del estudio exhaustivo de la intervención -ya sea por acción u omisión (Oszlak y O’Donnell, 2007) - del Estado sobre la cuestión migratoria, se han diferenciado numerosas dimensiones de análisis de la política migratoria argentina (Domenech y Pereira, 2017). Esta investigación se inscribe en la línea de aquellas que dieron cuenta de los cambios y continuidades entre diferentes instrumentos normativos de política migratoria, evidenciando una diferenciación y tensión entre la restricción y la selectividad (Ceriani Cernadas, 2016; Ceriani Cernadas y Morales, 2011; Courtis y Pacecca, 2007; Domenech, 2009; Le Gall y Sassone, 2007; Nejamkis, 2016; Novick, 2008, 2012; Sassone, 2004). Si bien los procesos y mecanismos de selección de población extranjera han sido más explícitos (Mármora, 2005) en algunos períodos de la historia argentina que en otros (Devoto, 2004), las discusiones académicas sobre las representaciones y prácticas que ayudan a construir las diferencias entre migrantes deseables e indeseables siguen vigentes (Domenech y Pereira, 2017).

A partir de estos antecedentes, esta pesquisa se inserta en la discusión que, tanto desde la historiografía como desde la sociología o la ciencia política, retoma la aplicación de las políticas públicas migratorias para focalizar en las tensiones entre las normas y las prácticas administrativas (Biernat, 2007; Devoto, 2001), o entre éstas y las diferentes instituciones involucradas (García, 2013) o entre todas las anteriores y los recursos humanos (Di Liscia, 2017), financieros o tecnológicos (Norambuena y Matamoros, 2016).

En cuanto a la metodología utilizada para este artículo, se realizó el revelo de bibliografía especializada en política migratoria argentina reciente, el repaso de la normativa migratoria relacionada con la migración venezolana por medio de la búsqueda en el portal de Información legislativa y documental dependiente del Ministerios de Justicia y Derechos Humanos (s/f) y de las acciones de política pública publicadas en el portal oficial del Estado argentino (Secretaría de Innovación Pública de la Jefatura de Gabinete de Ministros, s/f). A modo de fuentes complementarias de análisis, se utilizarán los resultados de entrevistas en profundidad realizadas a 15 migrantes venezolanos en el aglomerado Santa Rosa-Toay, Provincia de La

\footnotetext{
${ }^{3}$ La figura del Estado "gendarme" hace referencia a la ley $\mathrm{N}^{\circ} 22.439$ del Poder Ejecutivo Nacional, Ley General de Migraciones y de Fomento de la Inmigración, sancionada durante la última dictadura militar argentina en 1981. Se basaba en la óptica de seguridad en cuanto a la regulación migratoria: los migrantes indocumentados eran considerados ilegales y sujetos a la detención o expulsión por acción de la DNM sin orden judicial. Los ilegales no tenían acceso a la salud, educación ni a la justicia.
} 
4 Migración venezolana reciente en Argentina: una política migratoria selectiva...

Linares, M. D.

Pampa, Argentina, entre los años 2017 y 2019 y a funcionarios de la DNM Delegación La Pampa sobre la accesibilidad y aplicación de estas normativas migratorias. Se toma como unidad de análisis el conglomerado urbano que incluye las ciudades de Santa Rosa, Departamento Capital, de 105312 habitantes según el Censo 2010 y Toay, Departamento Toay, que cuenta con 12409 habitantes (INDEC, 2010). Aunque cada ciudad pertenece a una jurisdicción departamental diferente, Toay es la ciudad satélite más importante del Gran Santa Rosa, dada su cercanía geográfica y su relevancia demográfica.

Con el fin de organizar nuestro trabajo, comenzaremos definiendo los lineamientos conceptuales que guían el análisis de la política pública migratoria. En segundo lugar, describiremos el último cambio de paradigma de la política migratoria argentina, especialmente pero no exclusivamente desde la administración del presidente Macri. Luego indicaremos los resultados del relevo de aquellos instrumentos de política pública destinados a los ciudadanos venezolanos en Argentina. En cuarto lugar, se detallan los criterios de selectividad aplicados a este colectivo y se analizan las tensiones entre la política pública general y la selectiva. Por último, en la conclusión se retomarán los principales resultados de nuestro relevo e indicaremos posibles pistas de análisis.

\section{MARCO CONCEPTUAL}

El objetivo de este artículo supone abordar la migración internacional como un proceso sociopolítico y centrar su análisis en la institucionalidad. La sociología política y la ciencia política -y especialmente el campo de la gestión y administración pública- nos ofrecen una serie de herramientas conceptuales para comprender las formas en que el Estado argentino gestiona a los migrantes que habitan en su territorio. En principio, al enfocarnos en la normativa y acciones de la política migratoria, acordamos que el Estado, mediante las unidades e instituciones que lo componen, tiene la facultad de fijarse objetivos autónomos realizables mediante sus políticas públicas (Skocpol, 1995). Siguiendo una línea ya clásica, las políticas públicas se podrían definir como un conjunto de acciones y omisiones que manifiestan una modalidad de intervención del Estado en relación con una cuestión que concilia el interés de otros actores de la sociedad civil (Oszlak y O’Donnell, 2007).

Las políticas públicas migratorias que forman parte de la política de población serían las propuestas y metas elaboradas desde el aparato estatal con el fin específico de influir en el tamaño, la composición, el origen, la dirección, el asentamiento y la integración de los flujos migratorios espontáneos o pertenecientes al proceso global de planificación económico-social (Nejamkis, 2016). Nos referimos a una política migratoria selectiva cuando, desde el aparato estatal, se establecen criterios que caracterizan el tipo de migrante que debe predominar en función de origen, religión, sexo, edad, nivel educativo o socioeconómico, entre otros (Mármora, 2005).

Se utiliza en numerosos países y se ha utilizado en Argentina, ya sea con el fin de promover un tipo de flujo migratorio como para evitar el ingreso de flujos indeseables. Para comprender si la política migratoria destinada a los venezolanos se trata de una política selectiva, es necesario determinar si cuenta con al menos alguno de los criterios de selectividad. Estos criterios estuvieron vinculados, en la Argentina, a la capacidad laboral (agricultores a fines de 
los siglos XIX y principios del XX y obreros/técnicos industriales a mediados del siglo XX) y al origen étnico (migrantes que se integren con facilidad a la cultura argentina). A principios del siglo XX, un nuevo criterio definió las políticas selectivas: el ideológico, que implicaba impedir el arribo de todo migrante que, aunque cumpla con los otros criterios, sea asociado a ideas comunistas (Biernat, 2007). Otro rasgo de las políticas selectivas en la Argentina fue el criterio de encauzamiento, que suponían un la realización de un aporte inmediato a la necesidad económica del país mediante el direccionamiento de los migrantes a determinadas áreas productivas (Devoto, 2001).

Como explica Isuani (2012), una política pública requiere de un conjunto de instrumentos como condiciones básicas para que el Estado pueda cumplir sus objetivos. Sin estos instrumentos, las intenciones de los actores -principalmente los estatales- quedarían en meras acciones declarativas. Este autor propone tres "instrumentos o condiciones necesarias" como materializadores de la intervención del Estado: "un dispositivo normativo que estructure y oriente sus actividades, un dispositivo de gestión que las sostenga y concrete, y un conjunto de recursos básicos que las torne viables" (Isuani, 2012, p.33). En este trabajo, observaremos la política migratoria selectiva hacia los migrantes venezolanos en la Argentina a partir del relevo de los instrumentos normativos (compuestos por leyes, decretos y reglamentos que encuadran y autorizan a las acciones y a los actores intervinientes) y se identificarán los dispositivos de gestión y las “ventanillas" (Jelin, 2006) para llevar adelante las acciones. El análisis normativo de una política migratoria puede evidenciar, como indica Novick (2008), que éstas responden a modelos de sociedad ideológicamente configurados.

\section{GIRO RESTRICTIVO DE LA POLÍTICA PÚBLICA MIGRATORIA EN LA ARGENTINA}

La normativa vigente que regula la política migratoria argentina es, desde el año 2004, la Ley $\mathrm{N}^{\circ} 25.871$ (Ley de Migraciones $\mathrm{N}^{\circ}$ 25.871). Como se adelantó en la introducción, esta normativa contempla la perspectiva de los derechos humanos y el enfoque migratorio regionalista (Le Gall y Sassone, 2007) al aplicar el criterio de nacionalidad para la residencia temporaria (Arts. 23 y 28) que beneficia a los ciudadanos del Mercosur y asociados. Esta ley tiene un espíritu inclusivo que reconoce a la migración como un derecho humano fundamental que el Estado debe garantizar. Además, determina que los migrantes tienen derecho al acceso libre a los servicios de salud, justicia y educación, sin perjuicio de su condición migratoria. Que esta ley sea inclusiva no quiere decir que sea irrestricta o masiva: no reconoce los derechos políticos, una deuda que algunos investigadores y actores sociales (Ceriani Cernadas y Morales, 2011; Penchaszadeh, 2012) consideran como el talón de Aquiles de esta normativa.

En cuanto a su dispositivo de gestión, la DNM es el organismo de aplicación de la política migratoria y cuenta con una cobertura territorial federal. Las disposiciones y resoluciones emanadas de esta institución en el período 2004-2015 tuvieron como fin adecuarse mediante objetivos y acciones concretas a la nueva normativa migratoria (Linares, 2018). Desde el interior del organismo se buscaba pasar a ser una institución al servicio del migrante (colaborando en su inserción en el país y en el acceso a sus derechos) y no solamente un organismo de control (una de sus principales funciones, tanto de frontera como de permanencia (Linares, 2018). 
6 Migración venezolana reciente en Argentina: una política migratoria selectiva... Linares, M. D.

Esta política garantista -en su aspecto normativo y de gestión- encontró, desde el interior de la DNM, ciertos virajes restrictivos: las acciones tendientes al control aumentaban considerablemente en los años de elecciones nacionales, especialmente en 2011 y en 2015 (Linares y Melella, 2018). Estos giros restrictivos se podrían explicar por la confluencia de tres fenómenos que hacen de este tema una cuestión social sensible en la Argentina: a) el alto índice de población extranjera que reside en los distritos electorales más poblados (provincia de Buenos Aires y la Ciudad Autónoma de Buenos Aires); b) la recurrencia en los medios masivos de comunicación en la vinculación entre migraciones y delincuencia así como con efectos negativos de crisis económicas (desocupación, alta demanda en centros de salud y educativos, etcétera) y c) la imposibilidad de los extranjeros de ejercer su derecho a voto en elecciones nacionales. En suma, en épocas de elecciones tanto funcionarios del gobierno de Cristina Fernández (2007-2011 y 2011-2015) como de la oposición recurrían a la vinculación entre migrantes y criminalidad en actos políticos así como en los medios de comunicación.

Otros indicios de este viraje restrictivo ocurrieron luego del conflicto por las tierras del Parque Indoamericano del año $2010^{4}$ (Canelo, Gavazzo y Nejamkis, 2018), donde el entonces Jefe de la Ciudad Autónoma de Buenos Aires (CABA), Mauricio Macri, vinculó directamente a la migración internacional con el narcotráfico y otros delitos. Posteriormente, algunos referentes del partido justicialista de la administración de Fernández de Kirchner, como el exsecretario de Seguridad de la nación Sergio Berni en 2012 y el senador nacional Ángel Pichetto en 2014, propusieron la implementación de políticas más duras hacia los inmigrantes que generaron controversias al interior del gobierno nacional. Otras tensiones se originaron con la modificación del Código Procesal Penal Federal (Ley $\left.\mathrm{N}^{\circ} 27.063,2014\right)$ que en su artículo $\mathrm{N}^{\circ} 35$ permite la expulsión del país a personas extranjeras en situación irregular sorprendidas en flagrancia de un delito. Esta tensión entre la política inclusiva y la restrictiva atravesaba entonces todo el arco político de las dos fuerzas mayoritarias que disputarían la elección presidencial en Argentina en octubre del 2015: el Partido Justicialista y la alianza Cambiemos, conformada esta última por el tradicional Partido Radical y el PRO, liderado por Mauricio Macri.

Con la asunción de Mauricio Macri como presidente de la nación (2015-2019), se observaron los primeros signos de cambio de política migratoria. Al momento del conflicto por el Parque Indoamericano en 2010, Macri se había referido a los problemas de una migración descontrolada, el avance del narcotráfico y de la delincuencia y afirmó que el Estado no estaba cumpliendo su rol de controlar la migración. Ya a principios del año 2016, desde el gobierno nacional se promovieron entonces modificaciones en la aplicación de la política migratoria que reforzaron la idea de control en detrimento del servicio en el ámbito del dispositivo de gestión, la DNM, bajo la dirección de Horacio José García. Concretamente, se suspendió el Programa de Abordaje Territorial de la DNM (que recorría el país brindando información y asesoramiento

\footnotetext{
${ }^{4}$ En diciembre de ese año un grupo de personas tomó terrenos en el Parque Indoamericano, ubicado en la Comuna 8 de la Ciudad de Buenos Aires, caracterizada por poseer el más alto porcentaje de población migrante de toda la ciudad (23.4\%). La ocupación fue reprimida violentamente por la Policía Federal y la Metropolitana y, como respuesta, se acercaron miles de personas en apoyo a los manifestantes. El conflicto duró casi una semana y tuvo un salgo de tres muertos por la represión y enfrentamientos, todos migrantes.
} 
a migrantes); aumentaron de los operativos de control de permanencia en un 37 por ciento con respecto al 2015 (que había sido particularmente alto por ser año de elecciones, como explicamos); aumentaron las disposiciones de expulsión en un 70 por ciento (de 1908 en 2015 a 3258 en 2016); se creó un Área de Prevención de Delitos Migratorios en la DNM y se duplicó del costo de las tasas migratorias (Canelo, Gavazzo y Nejamkis, 2018; García y Nejamkis, 2018).

Otra de las acciones que demostró el tratamiento de las migraciones internacionales en tanto una cuestión de seguridad fue el anuncio, en 2016, de la creación de un Centro de Detención para infractores de la Ley de Migraciones en la Ciudad de Buenos Aires, mediante un convenio firmado por la Ministra de Seguridad Nacional Patricia Bullrich, su par de la CABA Fernando Ocampo y el Director de la DNM. Este controvertido centro de detención generó manifestaciones por parte de organizaciones sociales, de migrantes, de DDHH y de sectores académicos $\mathrm{y}$, hasta la fecha de escritura de este trabajo, no ha sido aún inaugurado.

En ese contexto, a principios del año 2017 se genera la reformulación más importante del dispositivo normativo de la política migratoria argentina. En enero de 2017 el presidente Macri firmó (sin debate legislativo) el Decreto de Necesidad y Urgencia $\mathrm{N}^{\circ} 70 / 2017$ (DNU № 70, 2017), que modificó sustancialmente la Ley de Migraciones. En los considerandos del decreto se vincula directamente a la migración con la criminalidad, utilizando términos como narcocriminalidad, seguridad pública, fraude a la ley migratoria o estar ante una situación crítica y deja en claro que los extranjeros que cometen delitos (con o sin condena) son amenazas reales y potenciales que deben ser eliminadas. El decreto permite la expulsión con trámite sumarísimo (en tres días) y sin actuación del poder judicial, de aquellos extranjeros que hayan cometido delitos dentro o fuera del país, y limita el derecho de reunificación familiar (Penchaszadeh y García, 2018).

Aunque la Cámara Federal de Apelaciones en lo Contencioso Administrativo Federal consideró al decreto "nulo de nulidad absoluta e insanable" y declaró su invalidez constitucional, los efectos del mismo continuaron así como las expulsiones por él amparadas (aproximadamente 125 confirmadas hasta mediados del año 2019). El caso siguió bajo estudio de la Corte Suprema de Justicia de la Nación y, en septiembre de 2019, el Comité de Protección de los Derechos de Todos los Trabajadores Migratorios y de sus Familiares de la Organización de Naciones Unidas instó al Estado argentino "a que adopte medidas inmediatas para derogar en la instancia pertinente el Decreto No 70/2017" (CMW-ACNUDH, 2019, p.3) así como a revisar todos los casos de expulsiones que se hayan realizado desde la sanción del DNU y los que aún están pendientes de resolución. Finalmente, el DNU 70/2017 fue derogado en el mes de marzo de 2021 por medio de otro decreto firmado por el presidente Alberto Fernández.

\section{POLÍTICA MIGRATORIA HACIA LOS MIGRANTES VENEZOLANOS EN EL CONTEXTO RESTRICTIVO}

El giro restrictivo anteriormente descripto no afectó a la totalidad de los migrantes internacionales, ya que a partir del año 2018 el Estado argentino movilizó recursos tanto humanos como tecnológicos y dispuso cambios institucionales destinados a los ciudadanos venezolanos. En este apartado se indican y describen esta política pública específica, a partir del relevo de las normativas (disposiciones y resoluciones) y acciones de política pública 
destinadas a facilitar la regularización documentaria y la inserción de los migrantes venezolanos en nuestro país.

Estos instrumentos y acciones, así como las instituciones encargadas de gestionarlos, fueron elaborados a partir del año 2018. De debe señalar que, hasta el mes de julio de 2017, los migrantes venezolanos gozaban de facilidades de radicación gracias al Acuerdo de Residencia para los Nacionales de los Estados Partes y Asociados del Mercosur, aprobado a nivel nacional mediante la Ley 25.902, publicada en el Boletín Oficial en Julio de 2004 (Ley N²5.902, 2004), que le daba un carácter de selectividad a la política migratoria argentina. Pero el 5 de agosto de 2017 Venezuela fue suspendida del bloque regional en aplicación del Protocolo de Ushuaia sobre Compromiso Democrático en el Mercosur, dejando a sus ciudadanos en una zona gris con respecto a los requisitos para su regularización migratoria en la Argentina.

En 2018 la administración del presidente Macri impulsó un conjunto de instrumentos de políticas públicas destinados a beneficiar a este colectivo migrante que, como veremos a continuación, excedieron la cuestión estrictamente migratoria. Relevamos cinco instrumentos normativos (dependientes de tres ministerios diferentes) y siete acciones de política pública, en las cuales participaron más de diez organismos estatales, todos elaborados e implementados entre los años 2018 y 2019. Luego de la sistematización de estos instrumentos identificamos cuatro líneas que describen esta política pública: a) Facilidades en cuanto a la documentación para la regularización migratoria, b) Facilidades para la convalidación de títulos universitarios, c) Inserción laboral de profesionales venezolanos y direccionamiento a áreas de vacancia en distintas provincias argentinas, y d) Defensa de los DDHH de ciudadanos venezolanos. En el cuadro número 1 se sintetiza la información recolectada en función del eje de política pública, el año, el instrumento de gestión y el tipo de intervención estatal, es decir, si se trata de un instrumento normativo o de una acción puntual.

Cuadro 1. Política pública argentina destinada a migrantes venezolanos: instrumentos normativos y acciones de política pública

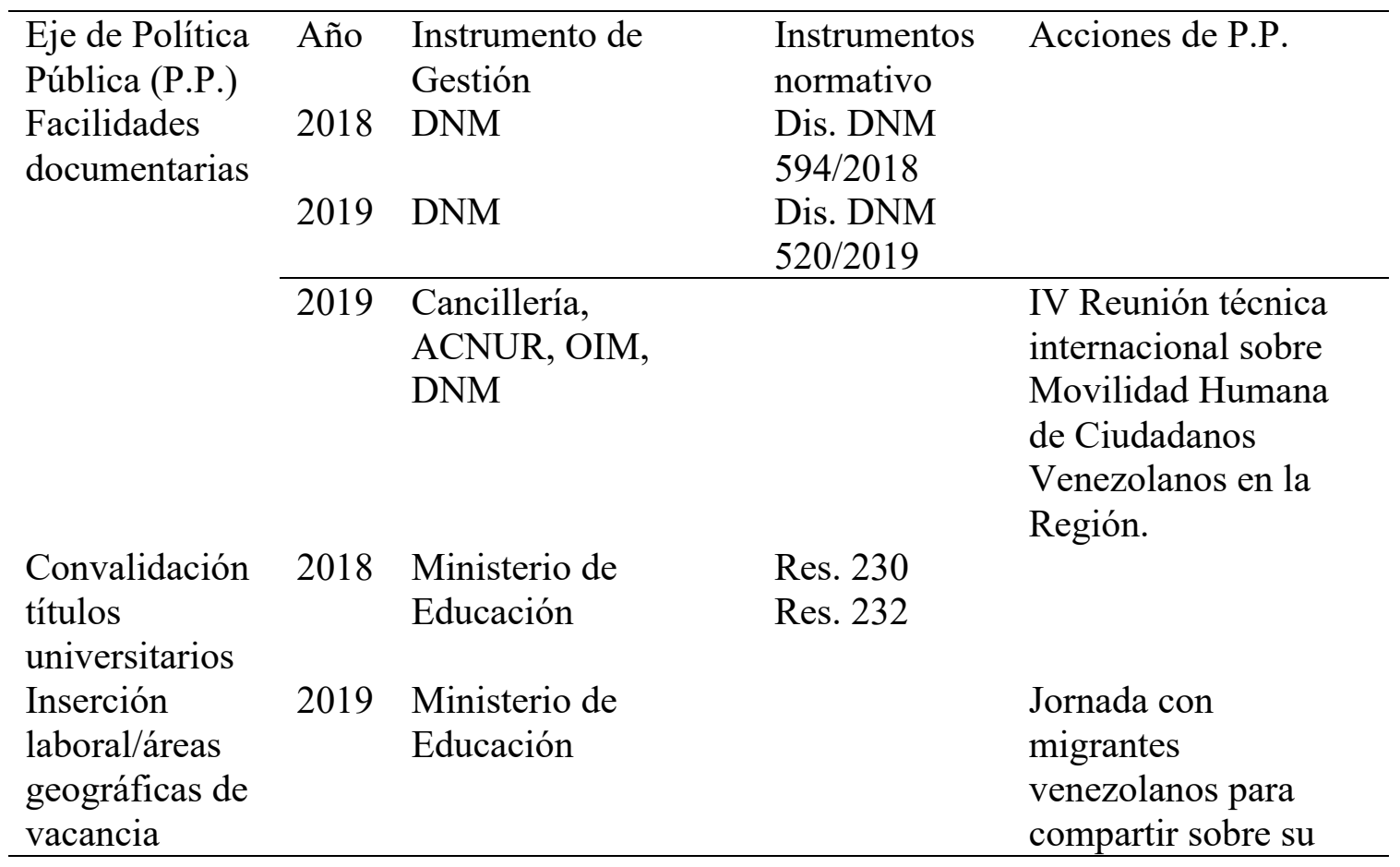




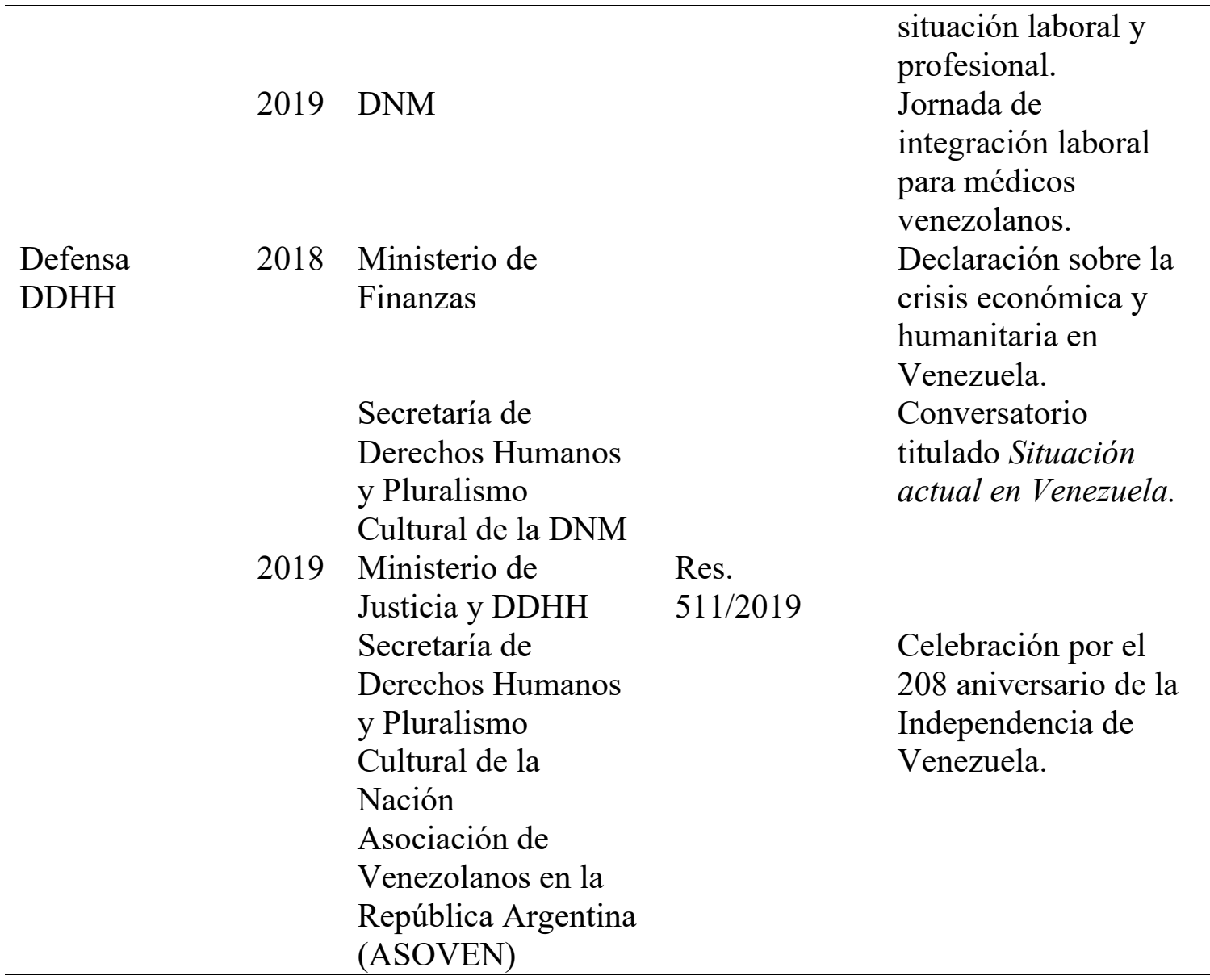

Fuente: Elaboración propia a partir de información de los portales oficiales del Ministerio de Justicia y Derechos Humanos (s/f) y de la Secretaría de Innovación Pública de la Jefatura de Gabinete de Ministros (s/f).

En cuanto a los instrumentos normativos, observamos un tratamiento gradual que busca brindar respuestas a algunos inconvenientes para la inserción de los migrantes venezolanos en el país. Con el fin de flexibilizar los requisitos para la regularización documentaria, en 2018 la Disposición 594 faculta a la DNM para "arbitrar medidas operativas y administrativas, previa evaluación y consideración de cada caso en particular, que permitan dar continuidad a los trámites migratorios de residencia iniciados por nacionales venezolanos" (Disposición 594, 2018, p.1). Mientras tanto, desde el Ministerio de Educación la Resolución 230-E/2018 autorizaba en su artículo 1 a la Dirección Nacional de Gestión Universitaria a "convalidar los títulos, diplomas o grados académicos universitarios expedidos por instituciones universitarias debidamente reconocidas por las autoridades competentes de la República Bolivariana de Venezuela" (Resolución 230, 2018, p.1). Seguidamente, el artículo 1 de la Res. 232-E/2018 establece "un tratamiento preferencial en los Trámites administrativos de reconocimiento de estudios de la Educación obligatoria [...] cursados en la República Bolivariana de Venezuela, a los fines de permitir el ingreso y Egreso de estudiantes a los establecimientos educativos de toda la República Argentina, mientras persista la ruptura del orden democrático en aquel país" [cursivas añadidas] (Resolución 232, 2018, p.1).

Durante el año 2019, la DNM emite un programa especial para migrantes venezolanos mediante la Disposición 520/2019 "para facilitar el ingreso al Territorio Nacional, la regularización de su condición migratoria y la inserción social en la comunidad de acogida" 
10 Migración venezolana reciente en Argentina: una política migratoria selectiva... Linares, M. D.

(Disposición 520, 2019, p.1). Se comienzan a aceptar como válidos documentación vencida y sólo partidas de nacimiento para menores para la radicación. Por su parte, el Ministerio de Justicia y Derechos Humanos habilita, a través de la Resolución 511/2019 (Resolución 511, 2019), la recolección de información y testimonios respecto de "posibles violaciones de Derechos Humanos que ocurran o hubiesen ocurrido en la República Bolivariana de Venezuela, que pudieran aportar ciudadanos venezolanos residentes en la República Argentina, y que resulten relevantes para una eventual remisión de estos a los organismos internacionales competentes" (Resolución 511, 2019, p.1).

En cuanto a las acciones analizadas, se trataron de actos/declaraciones y de jornadas de trabajo e intercambio de información. De esta manera, en el 2019 el Ministro de Finanzas estuvo a cargo de la Declaración sobre la crisis económica y humanitaria en Venezuela donde, con el mismo espíritu que el Conversatorio sobre la Situación actual de Venezuela, se analizaron "cifras que exhiben la gravedad de la situación y repasaron las acciones que desde distintas áreas de gobierno realiza Argentina para facilitar la inserción de los ciudadanos venezolanos en nuestro país" (Ministerio de Justicia y Derechos Humanos, 2018, párr. 2). En 2019 se realizó la celebración por el 208 aniversario de la Independencia de Venezuela, en donde desde la Secretaría de Derechos Humanos y Pluralismo Cultural de la Nación se declaró que "reafirmamos nuestro compromiso y nuestro acompañamiento en su lucha por recuperar la paz y la libertad" [cursivas añadidas] (Ministerio de Justicia y Derechos Humanos, 2019, párr. 1). Se realizaron dos jornadas sobre integración laboral, una para profesionales venezolanos y otra para médicos, con el fin de direccionarlos hacia espacios geográficos de vacancia. Por último, durante el 2019 varios organismos especializados en migrantes y refugiados participaron en la IV Reunión Técnica Internacional sobre Movilidad Humana de Ciudadanos Venezolanos en la Región. El Estado argentino propuso "una Tarjeta de Movilidad Regional para venezolanos además de proyectos de creación de Centros de Recepción e Integración como así también Centros de Orientación a Refugiados y Migrantes. En línea con estas propuestas se agregó también el proyecto de una plataforma de orientación de las migraciones y de desarrollo de capital humano" (Ministerio del Interior, 2019, párr. 5).

Estos instrumentos buscaban garantizar a los venezolanos de aquellos beneficios de los que gozaban como migrantes regionales gracias al Acuerdo de Residencia Mercosur antes que Venezuela sea suspendida como Estado parte del bloque. Significó entonces darle continuidad a un acuerdo intergubernamental del año 2004 -formulado en un contexto de cambio de paradigma de política migratoria-, pero mediante otros instrumentos de política pública. A partir del año 2018, esta continuidad se desarrolla en un contexto de cambio de la política migratoria general, de una perspectiva de inclusión y respeto a los DDHH hacia una concepción restrictiva volcada al control. Estimamos que el conjunto de instrumentos normativos y acciones de política pública formulados en el período de dos años manifiestan la existencia de una política migratoria selectiva explícita destinada a un colectivo específico. Los criterios de selección, observaremos con más detenimiento en el próximo apartado, respondieron a las cuatro cuestiones que conciliaban el interés del Estado: los problemas de regularización migratoria, la inserción laboral de los migrantes, el reconocimiento educativo y la defensa de sus Derechos Humanos. 


\section{CRITERIOS DE SELECTIVIDAD DE LOS MIGRANTES VENEZOLANOS}

Teniendo en cuenta los criterios de selectividad nombrados más arriba, en este caso detectamos la voluntad política y el esfuerzo por maximizar los beneficios de la migración venezolana en tanto recurso de conocimiento a direccionar hacia áreas geográficas de vacancia. Es importante considerar que, hasta el mes de mayo de 2018, fueron 11487 los ingenieros y técnicos venezolanos que tramitaron su radicación en la Argentina (Sala, 2019), lo que significaría para el país receptor la posibilidad de solucionar la carencia de ingenieros propios (un ingeniero cada 6600 habitantes). Frente al problema ya estructural de la fuga de cerebros venezolana desde fines de los años noventa (De La Vega, 2005; De la Vega y Vargas, 2014), la Argentina busca promover políticas que beneficien a las diferentes industrias y servicios nacionales. Los instrumentos normativos en materia educativa de convalidación de títulos y las acciones tendientes a informar a profesionales venezolanos sobre el mercado de trabajo y áreas de vacancia demuestran la presencia de dos criterios de selectividad: el laboral/profesional y el encauzamiento.

Por otro lado, se evidencia un nuevo criterio, el humanitario (Pereira, 2019), manifestado en las facilidades para la regularización migratoria y protección de los DDHH de los migrantes venezolanos. Este criterio, a su vez, puede combinarse con uno de carácter ideológico mediante el cual, mientras el Estado protege al migrante, pueda sentar posición en la condena a la crisis humanitaria de Venezuela. En los dispositivos normativos relevados y en las declaraciones de funcionarios en el marco de las acciones analizadas, la administración del presidente Macri declara que el gobierno de Nicolás Maduro ha roto el orden democrático en aquel país. Así como el Programa Siria de la DNM del año 2014 (Disposición 3951, 2014) aplicaba el criterio humanitario basándose en las terribles consecuencias del conflicto armado en ese país, el Programa para venezolanos es fundado en la consideración de que se ha quebrado "orden constitucional" en Venezuela y en la voluntad de la Argentina de "ayudar al pueblo venezolano que vive una crisis humanitaria sin precedentes en la historia" (Disposición 250, 2019, p.1). La disposición de la DNM del año anterior, se basaba en el "el agravamiento de la crisis política, social y humanitaria" (Disposición 594, 2018, p.1) de Venezuela y se recordaba que la Argentina, junto con los países miembros del Mercosur, habían decidido suspender a Venezuela del bloque por no considerar a su gobierno como democrático. La Resolución 511/2019 del Ministerio de Justicia se fundamenta en que la Argentina participa activamente en las peticiones ante organismos internacionales por la violación de los DDHH en Venezuela (Resolución 511, 2019). Esa resolución indica que, en septiembre de 2018, Argentina, Perú, Canadá, Colombia, Chile y Paraguay solicitaron ante la Fiscalía de la Corte Penal Internacional que se "inicie una investigación sobre la comisión de crímenes de lesa humanidad que habría tenido lugar en Venezuela bajo el gobierno del presidente Nicolás Maduro desde el año 2014" (Resolución 511, 2019, p.1).

Los criterios de la selectividad se sostienen en razones de capacidad laboral/profesional, en el encauzamiento de la mano de obra y en la protección de este colectivo en tanto "víctima" de una crisis humanitaria. Para cumplir con estos objetivos de política pública se deben poner a disposición no sólo a la autoridad migratoria, la DNM, sino también a otras agencias e instituciones estatales para gestionar de manera coordinada. Junto con la DNM, la Cancillería (Ministerio de Relaciones Exteriores y Culto) y la Comisión Nacional para los Refugiados 


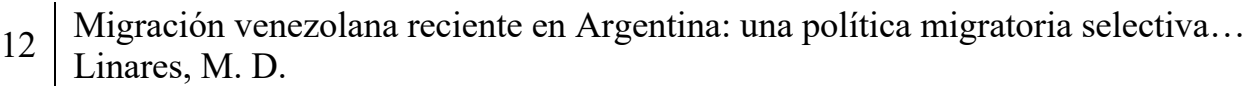

(Conare) realizan acciones para proteger a los migrantes venezolanos frente a las dificultades para cumplir con los requisitos de radicación ${ }^{5}$. Además, las otras líneas de acción (educación, inserción laboral profesional y DDHH) implican la actuación del Ministerio de Educación, el Ministerio de Justicia y DDHH mediante la Secretaría de DDHH y el Ministerio de Finanzas y otros organismos con el fin de realizar declaraciones sobre la crisis en Venezuela tendientes a clarificar y legitimar la orientación de estas políticas públicas.

\section{TENSIONES ENTRE LA POLÍTICA MIGRATORIA GENERAL Y LA SELECTIVA}

Del análisis del cuerpo normativo se pueden observar tensiones entre esta política selectiva y el giro restrictivo de la política pública migratoria general determinado por el DNU 70 del año 2017. En el acto en donde se anunció la Disposición DNM 594/2018 destinada a los venezolanos, el Ministro del Interior, Obras Públicas y Vivienda, Rogelio Frigerio, estableció que "si bien hemos sido muy abiertos al ingreso de los inmigrantes, también fuimos muy restrictivos desde el punto de vista de la seguridad, en estos últimos dos años" (Ministerio del Interior, 2018, párr. 3). Los instrumentos de política pública destinados a proteger los DDHH, facilitar la inserción y el desarrollo profesional/laboral de los migrantes venezolanos se llevan a cabo por el mismo Estado que, mediante DNU 70 del año 2017, vincula la criminalidad con la migración y estigmatiza a los migrantes regionales (Canelo, Gavazzo y Nejamkis, 2018). La concepción de control como cuestión securitaria de las migraciones regionales aparece también en la política de defensa nacional formulada bajo la administración del Presidente Macri, evidenciando nuevamente una tensión entre la política selectiva con la general. El Decreto 703/2018 "Directiva de Política de Defensa Nacional” (Decreto 703, 2018) no solo intenta distinguir entre los migrantes regionales deseables de los no deseables, sino que enlaza el apoyo a migrantes y refugiados venezolanos y la condena al gobierno de Venezuela con las cuestiones relacionadas a la criminalidad y narcotráfico, ejes fundamentales del viraje en la política migratoria:

El gobierno venezolano persiste en sus esfuerzos por consolidar un régimen autoritario que viola de manera sistemática las libertades fundamentales y los derechos políticos de sus ciudadanos. La crisis política, humanitaria, social y sanitaria que atraviesa la República Bolivariana de Venezuela atenta contra la consolidación de la zona de paz sudamericana, dado que afecta negativamente la estabilidad de la región, especialmente la de los países vecinos.

Estos últimos enfrentan un creciente flujo de refugiados que impacta sobre las economías limítrofes; generando condiciones propicias para la criminalidad organizada y el narcotráfico, y produciendo un efecto derrame hacia el resto de la región que debilita su gobernanza (Decreto 703, 2018, párr. 19).

Como se puede inferir en esta cita, no son los migrantes venezolanos los que podrían influir en el aumento de la criminalidad, sino que su impacto en las economías de los países limítrofes (estimamos que limítrofes de Argentina, así como de Venezuela: Colombia, Ecuador, Perú,

\footnotetext{
${ }^{5}$ Las demoras y los costos inaccesibles -el pago a gestores- para conseguir la documentación requerida a distancia dejan a los migrantes en una situación vulnerable. Por estas razones las normativas de la DNM buscan flexibilizar los requisitos a partir de prórrogas y de un programa especial que permite la presentación de documentación vencida.
} 
Bolivia, Paraguay) generaría condiciones para el narcotráfico que se derramarían sobre la Argentina. En este contexto, en que los migrantes deseables venezolanos pueden generar condiciones para el arribo de los indeseables de países limitrofes, la aplicación concreta de la política migratoria hacia ellos va a demostrar esta contradicción, basculando entre el servicio y el control securitario, como observaremos la aplicación de esta política en el caso de los migrantes en la Provincia de La Pampa.

Las entrevistas a migrantes venezolanos arribados a la Argentina fueron realizadas en el conglomerado urbano compuesto por la ciudad de Santa Rosa, que es la capital de la Provincia de La Pampa ${ }^{6}$, y su ciudad satélite, Toay. Aunque La Pampa no constituye un polo atractivo para los migrantes internacionales ${ }^{7}$, ha recibido nuevas corrientes migratorias en la última década (Linares, 2016), entre las que se destaca la migración venezolana. Este aumento fue significativo especialmente desde el año 2016, en que se resolvieron 300 pedidos de residencia en general, hasta llegar a los casi 800 pedidos en el 2018. De esa cifra total del año 2018, un alto funcionario de la DNM Delegación La Pampa confirmó que 307 fueron iniciados por ciudadanos venezolanos, y en el año 2019 se contabilizaban 122 hasta el mes de agosto, superando a las nacionalidades más tradicionales: paraguayos y bolivianos. Si bien estas cifras no son totalmente confiables porque se contabilizan dos trámites (de residencia y de prórroga de residencia) y porque algunas personas los realizan aún sin residir de forma permanente en la provincia, el aumento es significativo si lo comparamos con años anteriores. Según las personas migrantes entrevistadas, 150 venezolanos y venezolanas residían en Santa Rosa-Toay en 2019.

A partir de las 15 entrevistas en profundidad realizadas a migrantes venezolanos en el conglomerado Santa Rosa-Toay entre los años 2018 y 2019 pudimos conocer las particularidades de su vinculación con la normativa y los funcionarios argentinos. Todos los migrantes entrevistados relatan haber obtenido suficiente información sobre los trámites a realizar para su regularización documentaria en la DNM. Además, casi todos coinciden en haber recibido un trato correcto por parte de los empleados y funcionarios de la delegación de la DNM de La Pampa. Aun así, en cuanto a las facilidades sobre la tramitación documentaria, ninguno de los entrevistados pudo beneficiarse de la Disposición 520/2019 por haber realizado su regularización antes de esa fecha y casi todos relataron los inconvenientes encontrados a la hora de certificar partidas de nacimiento o antecedentes penales en su país de origen una vez arribados a la Argentina. De la misma manera, en ocasiones ser profesional, con su título convalidado o no, impidió la obtención de empleo menos calificados.

Se me presentó un problema con mi hijo mayor de 16 años, con su partida de nacimiento, porque resulta que la apostilla no me salió bien, no salió bien el código y en Migraciones no me la aceptaron. Y ese problema todavía lo tengo: ellos me siguen

\footnotetext{
${ }^{6}$ Ubicada geográficamente al centro de la República Argentina, con una superficie total de 143 $440 \mathrm{Km} 2$ y una población de 318951 habitantes según el último Censo Nacional del año 2010 (0.8\% de la población total del país) (INDEC, 2010).

${ }^{7}$ Mientras en el censo nacional del año 2001 el porcentaje de población extranjera sobre población nacional era de 1.15 por ciento, en el año 2010 fue de 1.08 por ciento.
} 
dando precaria, ${ }^{8}$ o sea válida por unos meses (A. Y. García, comunicación personal, 15 de mayo de 2018).

Ser profesional me restó: yo estaba mentalizado que necesitaba trabajar de cualquier cosa. A la señora (posible empleadora) le dije que si tenía que limpiar el piso, lo iba a hacer sin ningún problema. Pero a ella le daba pena, porque yo era médico y no le parecía bien que estuviese haciendo esas tareas (J. P. Rojas, comunicación personal, 22 de enero de 2018).

Cuando llegamos a Argentina, nuestros "antecedentes penales" ya estaban vencidos y tuvimos que hacer muchos trámites, hablamos con toda la gente de Migraciones asá y en Buenos Aires y al final salió bien, ipero fue un milagro! (D. P. Díaz, comunicación personal, 10 de febrero de 2019).

Finalmente, el giro restrictivo de la política migratoria general afectó indirectamente a dos de los migrantes venezolanos entrevistados: una mujer y un hombre (no se conocen entre sí) fueron detenidos por la policía provincial en dos oportunidades por averiguación de antecedentes. Según los entrevistados, la policía los paró por la calle sin sospecha de delito y sólo para controlar sus documentos, pero en ambos casos los mantuvieron detenidos en los destacamentos policiales en Santa Rosa y en Toay, por más de tres horas a cada uno.

¡Me dieron el DNI (documento nacional de identidad) tan rápido en la DNM que estuve presa por eso! [...] La policía me pidió el DNI y, como me lo sacaron en menos de un mes, ellos pensaron que era falso. Dos horas me tuvieron detenida. ¡Esa fue la experiencia, de todas, la más fea! Ellos llamaron a Migraciones, a lo de los antecedentes penales, para verificar todo, todito. En la DNM me trataron todo muy bien, hasta me exoneraron el costo de los trámites de mi hijo, no sé por qué. Pero en la policía estaban extrañados que ha dieran el DNI tan rápido (O. S. Hernández, comunicación personal, 10 de junio de 2018).

En dos oportunidades me ha pasado, con la Policía, que hay te tienen que sacar "la ficha", no sé... me ha parado la policía, supuestamente porque se dan cuenta que soy extranjero y, bueno, me ha tocado ir a la comisaría, adentro. Una vez uno me dijo algo feo pero me quedé callado. Aquí en Toay y también en Santa Rosa me lo hicieron. Me dijeron que tenían potestad provincial. Salvo ese policía en Santa Rosa, fueron todos respetuosos. Pero perdí cada vez tres horas de mi tiempo (A. Costa, comunicación personal, 27 de julio de 2018).

Estas detenciones arbitrarias por parte de la policía provincial indican que la vinculación entre migraciones y delincuencia no opera solamente en el plano discursivo de la nueva política migratoria restrictiva. Mientras el Estado pone a disposición secretarios para recibir denuncias de violaciones a los DDHH sufridas por venezolanos en su país, otro instrumento de gestión del mismo Estado, las fuerzas de seguridad, detienen arbitrariamente a los mismos venezolanos sospechados de haber cometido un delito (falsificación documentaria).

A partir del análisis de estas tensiones entre la política migratoria general y la política selectiva es necesario detenernos en la distinción entre políticas programáticas y coyunturales. Si bien ambas son una respuesta institucional frente al fenómeno migratorio, las políticas programáticas son el resultado de un proyecto político mayor que incluye aspectos económicos,

\footnotetext{
${ }^{8}$ Se refiere a una de las categorías de residencia que contempla la Ley 25.871; vale aclarar que la residencia precaria tiene una duración de 180 días.
} 
sociales, culturales más amplios (Mármora, 2005). Un ejemplo de política migratoria programática fue la resultante de la Ley 25.871, dado que se trató de un proyecto de ley debatido durante varios años en ambas cámaras legislativas, consensuado con organizaciones de la sociedad civil, entre ellas organizaciones de migrantes en Argentina, y en donde se tuvo en cuenta el contexto político y social en el cual se enmarcaban los flujos migratorios en el país (Novick, 2012). Por otro lado, las políticas migratorias coyunturales se caracterizan por ser una reacción a una presión migratoria del momento, que no responden a una planificación global y que tampoco son pensadas como de largo alcance (Mármora, 2005).

En cuanto a los cambios de la política migratoria general, el DNU 70/2017 se relaciona a la visión securitista y criminalística de las migraciones que primó durante la década de los noventa en la Argentina, cuando la migración proveniente de los países vecinos era considerada una amenaza al orden económico y social (Pereira, 2019). Paralelamente, se aplica desde el año 2018 una política selectiva por criterios laborales y de encauzamiento a otros migrantes regionales, los venezolanos. Encontramos entonces una política migratoria compuesta por normativas de diferentes jerarquías, en donde se superponen políticas de estado y políticas coyunturales que se excluyen entre sí. Mientras tanto, la política general obstaculiza la aplicación de la política selectiva hacia los venezolanos. Estas políticas, tanto las programáticas como las coyunturales, están atravesadas a su vez por diversas institucionalidades estatales que las gestionan según sus áreas de incumbencia, con resultados en ocasiones contradictorios. Observamos así, como sucedió en otros momentos de la historia argentina, una yuxtaposición de instrumentos normativos que proponen criterios de selección y restricción complejos contradictorios, gestionados por numerosos organismos generando tramas (Devoto, 2001) de políticas públicas confusas, incongruentes $\mathrm{y}$, finalmente, ineficientes en cuanto al cumplimiento de sus objetivos.

\section{CONCLUSIONES}

Este trabajo tuvo como objeto relevar la normativa migratoria destinada al colectivo de venezolanos así como las acciones concretas promovidas desde la administración del presidente Macri en la Argentina a través de la DNM y otros organismos, para determinar si se trató de una política selectiva en el contexto del cambio restrictivo de la política migratoria general. Para ello fue necesario describir el instrumento normativo de política pública que se aplica en Argentina para regular la cuestión migratoria desde el año 2004 (Ley de Migraciones $\left.\mathrm{N}^{\circ} 25.871\right)$ y se indicaron brevemente algunos de los desafíos que este instrumento implicó para el dispositivo de gestión en la materia, es decir, la DNM. Luego pudimos observar la manera en que se generó el viraje de política pública describiendo sus instrumentos principales, en especial el DNU 70/2017 y las consecuencias que el mismo tuvo en la concepción de la cuestión migratoria.

Frente a este cambio de paradigma que vincula -una vez más en la historia de la Argentinaa la migración regional con la criminalidad organizada y el narcotráfico, pusimos de relieve los instrumentos normativos y las acciones de las que se valió el Estado argentino para promover, direccionar y proteger a un colectivo migrante específico: los ciudadanos provenientes de Venezuela. Estos instrumentos de política pública dan cuenta de una selectividad manifiesta 
que se caracteriza por el abordaje de cuatro líneas: documentaria/migratoria, educativa, inserción laboral y protección de los DDHH.

Estas líneas de política pública permitieron la identificación de tres criterios de selección. Por un lado se descubrió un criterio laboral, manifestado en las normativas educativas, que demuestra el interés del Estado por maximizar el beneficio de la migración cualificada proveniente de Venezuela. Por otro lado, se evidenció el criterio de encauzamiento, mediante las acciones destinadas a direccionar a profesionales hacia ciertas áreas de vacancia. Por otro lado, estimamos que existió un criterio humanitario e ideológico que se manifestó en la normativa y en la colaboración para la denuncia de violaciones a los DDHH de migrantes venezolanos al mismo tiempo que se condenaba al gobierno de Nicolás Maduro. Estos criterios implicaron la diversificación de los instrumentos de gestión encargados de la cuestión.

El análisis de la política selectiva puso de manifiesto las tensiones entre ésta y la política migratoria general, que se desprende del DNU 70/2017. Se detectaron sentidos contrapuestos entre una y otra con respecto a la valorización de los migrantes regionales. Mientras el DNU 70/2017 y la política de Defensa Nacional vinculan a los migrantes de la región con el crimen y el narcotráfico, se beneficia solamente a unos migrantes específicos: los venezolanos. Pese a este beneficio, la ambigüedad de sentidos se manifestó en relación a la aplicación de la política migratoria. La particularidad de ser uno de los pocos colectivos migrantes beneficiados por una política migratoria selectiva en un marco de restricción y sospechas, no eximió a los migrantes venezolanos entrevistados de las arbitrariedades de las fuerzas de control. La detención por averiguación de antecedentes por parte de la fuerza policial es un claro ejemplo de esto.

Se desprende de estas observaciones que el Estado argentino operó para el caso de Venezuela en dos direcciones opuestas. Por un lado condenó al gobierno venezolano y promovió su suspensión del Mercosur, evaluó y emitió comunicados sobre la situación financiera de ese país y denunció al gobierno por delitos de lesa humanidad ante organizaciones internacionales, marcando un lineamiento claro de política exterior. Mientras que, por otro lado, declaró su interés y puso a disposición una serie de instrumentos de política pública interna para beneficiar a la población venezolana que residía en la Argentina. Se trató de una política interna destinada a subsanar las consecuencias indeseadas de una política exterior, como fue el caso de la suspensión de Venezuela del Mercosur y el desamparo en el que quedaron sus ciudadanos residiendo en la Argentina. Coexisten así políticas migratorias programáticas y coyunturales, así como generales y selectivas contradictorias o con sentidos contrapuestos, lo cual deja abierta la posibilidad de utilizarlas alternativamente en beneficio así como en detrimento de distintos colectivos migrantes según la conveniencia política. Esta yuxtaposición, tanto de instrumentos normativos como de instituciones encargadas de su gestión, revela el entramado confuso de la política migratoria Argentina desde el año 2017. Mientras tanto, el flujo venezolano no se detiene y es necesaria una política de Estado coherente que les garantice el pleno goce de sus derechos, así como el de "todos los hombres del mundo que quieran habitar en el suelo argentino" (Constitución de la Nación Argentina, 2010, p.91). 


\section{REFERENCIAS}

Biderbast, P. y Núñez, M. E. (2018). Del Río de la Plata al Orinoco y viceversa. Patrones y flujos migratorios entre Argentina y Venezuela. En J. Koechlin y J. Eguren (Eds.), El éxodo venezolano: entre el exilio y la emigración, (pp. 135-166). Madrid: Observatorio Iberoamericano sobre Movilidad Humana, Migraciones y Desarrollo.

Biernat, C. (2007). ¿Buenos o útiles?: la política inmigratoria del peronismo. Buenos Aires: Biblos.

Canelo, B. (2016). Migración y políticas públicas desde el margen. Acciones y omisiones estatales en un parque de la Ciudad de Buenos Aires. Migraciones Internacionales, 8(30), 125-153. Recuperado de https://doi.org/10.17428/rmi.v8i3.617

Canelo, B., Gavazzo, N. y Nejamkis, L. (2018). Nuevas (viejas) políticas migratorias en la Argentina del cambio. Si Somos Americanos, 18(1), 150-182. Recuperado de https://dx.doi.org/10.4067/S0719-09482018000100150

Ceriani Cernadas, P. (2016). Ampliación de derechos en tiempos de crisis: la política migratoria en Argentina desde 2003. Red Universitaria sobre Derechos Humanos y Democratización para América Latina, 5(8), 14-47.

Ceriani Cernadas, P. y Morales, D. (2011). Argentina. Avances y asignaturas pendientes en la consolidación de una política migratoria basada en los derechos humanos. Buenos Aires: Centro de Estudios Legales y Sociales (CELS)/Federación Internacional de Derechos Humanos (FIDH).

Comité de Protección de los Derechos de Todos los Trabajadores Migratorios y de sus Familiares (CMW - ACNUDH). (2019). Observaciones finales sobre el segundo informe periódico de la Argentina (CMW/C/ARG/2). Recuperado de https://tbinternet.ohchr.org/Treaties/CMW/Shared\%20Documents/ARG/CMW_C_ARG CO_2_37078_S.pdf

Constitución de la Nación Argentina: publicación del Bicentenario. (2010). Buenos Aires: Corte Suprema de Justicia de la Nación / Biblioteca del Congreso de la Nación / Biblioteca Nacional. Recuperado de https://bibliotecadigital.csjn.gov.ar/Constitucion-de-la-NacionArgentina-Publicacion-del-Bicent.pdf

Courtis, C. y Pacecca, M. I. (2007). Migración y derechos humanos: una aproximación crítica al "nuevo paradigma" para el tratamiento de la cuestión migratoria en la Argentina. Revista Jurídica de Buenos Aires. 183-200. Recuperado de https://silo.tips/queue/migracion-y-derechos-humanos-una-aproximacion-critica-al-nuevoparadigma-para-el?\&queue id=-1\&v=1627143514\&u=MTkwLjEwOC41Ni43Nw==

Decreto de Necesidad y Urgencia N 70/2017, Migraciones, Modificación de Ley núm. 25.871. Boletín Oficial de la República Argentina, Buenos Aires, 30 de enero 2017. Recuperado de http://servicios.infoleg.gob.ar/infolegInternet/anexos/270000-274999/271245/norma.htm

Decreto 703/2018, Directiva de Política de Defensa Nacional. Boletín Oficial de la Republica Argentina, Buenos Aires, 31 de julio de 2018. Recuperado de http://servicios.infoleg.gob.ar/infolegInternet/verNorma.do?id=312871

De La Vega, I. (2005). Mundos en movimiento. El caso de la movilidad y migración de los científicos y tecnólogos venezolanos. Caracas: Fundación Polar.

De la Vega, I. y Vargas, C. (2014). Emigración intelectual y general en Venezuela: una mirada desde dos fuentes de información. Bitácora-e Revista Electrónica Latinoamericana de Estudios Sociales, Históricos y Culturales de la Ciencia y la Tecnología, (1), 66-96. 
\begin{tabular}{l|l}
18 & Migración venezolana reciente en Argentina: una política migratoria selectiva... \\
Linares, M. D.
\end{tabular}

Devoto, F. (2001). El revés de la trama: políticas migratorias y prácticas administrativas en la Argentina (1919- 1949). Desarrollo Económico: Revista de Ciencias Sociales, 41(162), 282-303.

Devoto, F. (2004). Las políticas migratorias de Francia y Argentina en el largo plazo. Estudios Migratorios Latinoamericanos, 18(53), 121-153.

Di Liscia, M. S. (2017). Inmigración, salud y burocracia. Casos y perspectivas de análisis (1876-1920). En M. S. Di Liscia y G. Soprano (Eds.), Burocracias estatales. Problemas, enfoques y estudios de caso (entre fines del siglo XIX y XX), (pp. 43-60). Rosario, Argentina: Prohistoria.

Dirección Nacional de Migraciones. (s/f). Panorama radicaciones 2011-2015. Migraciones. Ministerio del Interior. Recuperado de http://www.migraciones.gov.ar/pdf/estadisticas/radicaciones_2011-2015.pdf

Dirección Nacional de Migraciones. (s/fa). Radicaciones resueltas 2016. Migraciones. Ministerio del Interior. Recuperado de http://www.migraciones.gov.ar/pdf/estadisticas/radicaciones_resueltas_2016.pdf

Dirección Nacional de Migraciones. (s/fb). Radicaciones resueltas 2017. Migraciones. Ministerio del Interior. Recuperado de http://www.migraciones.gov.ar/pdf/estadisticas/radicaciones_resueltas 2017.pdf

Dirección Nacional de Migraciones. (s/fc). Radicaciones resueltas 2018. Migraciones. Ministerio del Interior. Recuperado de http://www.migraciones.gov.ar/pdf/estadisticas/radicaciones_resueltas_2018.pdf

Dirección Nacional de Migraciones. Ciudad de Buenos Aires, 29 de enero de 2019. Recuperado de http://servicios.infoleg.gob.ar/infolegInternet/anexos/315000319999/319449/norma.htm

Disposición 3915/2014. Programa Siria, Dirección Nacional de Migraciones. Ciudad de Buenos Aires, 14 de Octubre de 2014. Recuperado de http://servicios.infoleg.gob.ar/infolegInternet/anexos/235000239999/236705/norma.htmDisposición 520/2019

Disposición 594/2018, Dirección Nacional de migraciones. Ciudad de Buenos Aires, 14 de febrero de $2018 . \quad$ Recuperado de http://servicios.infoleg.gob.ar/infolegInternet/verNorma.do?id=306895

Domenech, E. (2009). La visión estatal sobre las migraciones en la argentina reciente. De la retórica de la exclusión a la retórica de la inclusión. En E. Domenech (Comp.), Migración y política: el Estado interrogado. Procesos actuales en Argentina y Sudamérica, (pp. 2170). Córdoba: UNC.

Domenech, E. y Pereira, A. (2017). Estudios migratorios e investigación académica sobre las políticas de migraciones internacionales en Argentina. Íconos. Revista de Ciencias Sociales, Migraciones internacionales en América Latina: miradas críticas a la producción de un campo de conocimientos, (58), 83-108. Recuperado de https://doi.org/10.17141/iconos.58.2017.2487

García, L. (2013). Nueva política migratoria argentina y derechos de la movilidad. Implementación y desafios de una politica basada en derechos humanos a través de las acciones ante el Poder Judicial (2004-2010) (Tesis Doctoral). Universidad de Buenos Aires. https://www.academia.edu/16424966/TESIS DOCTORAL Nueva_pol\%C3\%ADtica mi gratoria y_derechos_de la_movilidad_Implementaci $\% \mathrm{C} 3 \% \mathrm{~B} 3 \mathrm{n} \_\mathrm{y} \_$desaf $\% \mathrm{C} 3 \% \mathrm{ADos}$ de 
una pol\%C3\%ADtica basada en derechos humanos a trav\%C3\%A9s de las accione s ante el Poder Judicial 20042010 Tesis doctoral Facultad de Derecho Universidad de Buenos_Aires_Sept 2013

García, L. y Nejamkis, L. (2018). Regulación migratoria en la Argentina actual: del "modelo" regional al recorte de derechos. Autoctonía. Revista de Ciencias Sociales e Historia, 2(2), 219-241. Recuperado de http://dx.doi.org/10.23854/autoc.v2i2.55

Instituto Nacional de Estadística y Censos de la República Argentina (INDEC). (2010). Censo Nacional de Población, Hogares y Viviendas 2010. Provincia de La Pampa. Población total y variación intercensal absoluta y relativa por departamento. Años 2001-2010. Recuperado de https://www.indec.gob.ar/indec/web/Nivel4-CensoProvincia-3-999-42-000-2010

Isuani, F. (2012). Las capacidades estatales. En C. Alza Barco (Ed.), VI Seminario de Reforma del Estado: Gestión pública: balance y perspectivas, (pp. 25-43). Lima: Fondo Editorial de la Pontificia Universidad Católica del Perú.

Jelin, E. (2006). Migraciones y Derechos: instituciones y prácticas sociales en la construcción de la igualdad y la diferencia. En A. Grimson y E. Jelin (Comps.), Migraciones regionales hacia la Argentina. Diferencia, desigualdad y derechos, (pp. 47-68). Buenos Aires: Prometeo.

Koechlin, J., Vega, E. y Solórzano, X. (2018). Migración Venezolana al Perú: proyectos migratorios y respuesta del Estado. En J. Koechlin y J. Eguren (Eds.), El éxodo venezolano: entre el exilio y la emigración, (pp. 47-96). Madrid: Observatorio Iberoamericano sobre Movilidad Humana, Migraciones y Desarrollo.

Le Gall, J. y Sassone, S. M. (2007). Tournant des politiques migratoires en Argentine. Vers une nouvelle politique territoriale? EchoGéo, (3), 1-11. http://doi.org/10.4000/echogeo.1850

Ley $\mathrm{N}^{\circ}$ 22.439. Ley General de Migraciones y de Fomento de la Inmigracion $\mathrm{N}^{\circ} 22.439$. Ciudad de Buenos Aires, 23 de marzo de 1981. Recuperado de http://servicios.infoleg.gob.ar/infolegInternet/anexos/15000-19999/16176/norma.htm

Ley de migraciones $\mathrm{N}^{\mathrm{0}}$ 25.871, Migraciones Nuevo Régimen Legal. Boletín Oficial del Congreso de la Nación Argentina, Buenos Aires, 21 de enero de 2004. Recuperado de http://servicios.infoleg.gob.ar/infolegInternet/verNorma.do?id=92016

Ley $\mathrm{N}^{\circ}$ 25.902. Acuerdos. Residencia nacionales del Mercosur, Bolivia y Chile. Boletín Oficial del Congreso de la Nación Argentina, Buenos Aires, 16 de julio de 2004. Recuperado de http://servicios.infoleg.gob.ar/infolegInternet/verNorma.do?id=96649

Ley N ${ }^{\circ}$ 27.063, Código Procesal Penal Federal. Boletín Oficial del Congreso de la Nación Argentina, Buenos Aires, 10 de diciembre de 2014. Recuperado de http://servicios.infoleg.gob.ar/infolegInternet/verNorma.do?id=239340

Linares, M. D. (2016). Trayectorias migratorias e inserción laboral de migrantes recientes en Santa Rosa-Toay (La Pampa, Argentina). Pilquen Sección Ciencias Sociales, 19(4), 32-46.

Linares, M. D. (2017). Política migratoria y capacidad estatal: la Dirección Nacional de Migraciones (República Argentina) entre los años 2004 y 2015. Polis, 16(48), 245-270. http://dx.doi.org/10.32735/S0718-6568/2017-N48-1278

Linares, M. D. y Melella, C. (2018). La Dirección Nacional de Migraciones entre 2008 y 2015: identidad institucional en disputa. Postdata Revista de Reflexiones y Análisis Plítico, 23(1), 213-238. Recuperado de http://www.revistapostdata.com.ar/2018/05/la-direccion-nacional- 
\begin{tabular}{l|l}
20 & $\begin{array}{l}\text { Migración venezolana reciente en Argentina: una política migratoria selectiva... } \\
\text { Linares, M. D. }\end{array}$
\end{tabular}

de-migraciones-entre-2008-y-2015-identidad-institucional-en-disputa-argentinas-nationaldirection-of-migration-2008-2015-disputes-about-institutional-identity-dolores-li/

Mármora, L. (2002). Las políticas de migraciones internacionales. Buenos Aires: Paidós.

Ministerio del Interior. (2018). Nuestro país abre las puertas a los venezolanos que quieran formar parte del crecimiento argentino. Ministerio del interior, 15 de febrero de 2018. Recuperado de https://www.argentina.gob.ar/noticias/nuestro-pais-abre-las-puertas-losvenezolanos-que-quieran-formar-parte-del-crecimiento

Ministerio de Justicia y Derechos Humanos. (s/f). Infoleg. Portal de Información legislativa y documental. Argentina. Recuperado de http://www.infoleg.gob.ar/

Ministerio de Justicia y Derechos Humanos. (2018). Conversatorio: situación actual en Venezuela, 8 de noviembre de 2018. Recuperado de https://www.argentina.gob.ar/noticias/conversatorio-situacion-actual-en-venezuela

Ministerio de Justicia y Derechos Humanos. (2019). Concierto por la Independencia de Venezuela, 22 de julio de $2019 . \quad$ Recuperado de https://www.argentina.gob.ar/noticias/concierto-por-la-independencia-de-venezuela

Ministerio del Interior. (2019). Avances en la gestión regional de los migrantes venezolanos, 5 de julio de 2019. Recuperado de https://www.argentina.gob.ar/noticias/avances-en-lagestion-regional-de-los-migrantes-venezolanos

Muñoz, R. (2017). La potestad de dispensa por razones de índole familiar, como facultad discrecional -exclusiva- de la Dirección Nacional de Migraciones. Estudios sobre Jurisprudencia, (3), 20-36. Recuperado de https://jurisprudencia.mpd.gov.ar/Estudios/2017.3.\%20La\%20potestad\%20de $\% 20$ dispensa $\% 20$ como $\% 20$ facultad $\% 20$ discrecional $\% 20 \% \mathrm{E} 2 \% 80 \% 93$ exclusiva $\% \mathrm{E} 2 \% 80 \% 93 \% 20 \mathrm{de} \%$ 201a\%20Direcci\%C3\%B3n\%20Nacional\%20de\%20Migraciones.pdf

Nejamkis, L. (2016). Políticas migratorias en la Argentina 1976-2010. De la Doctrina de Seguridad Nacional a la consolidación del Derecho Humano a la migración. Buenos Aires: Prometeo.

Norambuena, C. y Matamoros, R. (2016). Política migratoria Argentina: una mirada desde el institucionalismo histórico. Si Somos Americanos. Revista de Estudios Transfronterizos, 16(2), 45-72. Recuperado de https://www.redalyc.org/articulo.oa?id=337950844002

Novick, S. (Comp.). (2008). Las migraciones en América Latina. Políticas, culturas y estrategias. Buenos Aires: CLASCO.

Novick, S. (Dir.). (2012). Migraciones y Políticas Pública: Nuevos escenarios y desafios. Buenos Aires: Catálogos.

Oszlak, O. y O’Donnell, G. (2007). Estado y políticas estatales en América latina: hacia una estrategia de investigación. En C. H. Acuña (Comp.), Lecturas sobre el Estado y las políticas públicas: Retomando el debate de ayer para fortalecer el actual, (pp. 555-584). Buenos Aires: Jefatura de Gabinete de Ministros/Estudio CEDES.

Pedone, C. y Mallimaci, A. (2019). Trayectorias laborales de la población venezolana en la Ciudad Autónoma de Buenos Aires. En C. Blouin (Coord.), Después de la llegada. Realidades de la migración venezolana, (pp. 129-148). Lima: Themis.

Penchaszadeh, A. P. (2012). Migraciones y derechos políticos: ¿Democratización y extensión de la ciudadanía o nuevas formas de la extranjerización en democracia? En S. Novick (Dir.), Migraciones y Políticas Públicas: nuevos escenarios y desafios, (pp. 39-62). Buenos Aires: Catálogos. 
Penchaszadeh, A. P. y García, L. (2018). Política migratoria y seguridad en Argentina hoy: ¿el paradigma de derechos humanos en jaque?. URVIO Revista Latinoamericana de Estudios de Seguridad, (23), 91-109. Recuperado de https://dx.doi.org/10.17141/urvio.23.2018.3554

Pereira, A. (2019). El nexo entre migración, seguridad y derechos humanos en la política migratoria de Argentina (1990-2015). Revista Desafios, 31(1), 237-309. Recuperado de https://doi.org/10.12804/revistas.urosario.edu.co/desafios/a.6031

Resolución E 230/2018, Convalidación de títulos diplomas o grados académicos universitarios. Ciudad de buenos Aires, 7 de febrero de 2018. Recuperado de http://servicios.infoleg.gob.ar/infolegInternet/anexos/305000-309999/306732/norma.htm

Resolución E 232/2018, Reconocimiento de estudios de la Educación Obligatoria - República de Venezuela. Ciudad de Buenos Aires, 7 de febrero de 2018. Recuperado de http://servicios.infoleg.gob.ar/infolegInternet/anexos/305000-309999/306734/norma.htm

Resolución 511/2019. Secretaría de Derechos Humanos y Pluralismo Cultural - Instrúyase, Ministerio de Justicia y Derechos Humanos. Boletín Oficial, núm. 34158, Buenos Aires, 22 de julio de 2019 . Recuperado de http://servicios.infoleg.gob.ar/infolegInternet/verNorma.do? id=325394

Sala, G. A. (2019). Ingenieros venezolanos residentes en la República Argentina. Recuperado de http://argentina.iom.int/co/sites/default/files/publicaciones/INGENIEROS.pdf

Sassone, S. M. (2004). Políticas migratorias y la integración en el Mercosur: actores institucionales y tensiones emergentes en la República Argentina, GEODEMOS, (7/8), 179220 .

Secretaría de Innovación Pública, Jefatura de Gabinete de Ministros, Argentina. (s/f). Página web. Gobierno de Argentina. Recuperado de https://www.argentina.gob.ar/

Skocpol, T. (1995). El estado regresa al primer plano: estrategias de análisis en la investigación actual. En R. Grompone (Ed.), Instituciones politicas y sociedad. Lecturas introductorias, (pp. 92-129). Lima: IEP.

United Nations High Commissioner for Refugees (UNHCR). (2021). Venezuela Situation. Operational Data Portal. Refugee Situations. Recuperado de https://data2.unhcr.org/es/situations/vensit 